\title{
Design, Modelling and Implementation of a Push-Pull Converter used in Grid Connected Photovoltaic Systems
}

\author{
Angie Alejandra Rojas Aldana, Oscar Ernesto Barrera Beltrán and Cesar Leonardo Trujillo \\ Rodríguez*
}

Laboratorio de Investigación en Fuentes Alternativas de Energía, Facultad de Ingeniería, Universidad Distrital Francisco José de Caldas, Bogotá D.C., Colombia.

Received 9 February 2018; Accepted 2 August 2018

\begin{abstract}
This paper presents the modelling, design and implementation of a DC-DC converter integrated into a two-stage photovoltaic microinverter operating in grid connected mode. A push-pull topology has been chosen because it provides galvanic insulation and adjusts the DC voltage from the photovoltaic panel to an appropriate voltage with the implementation of a current-injected control (CIC). The push-pull electrical design is presented for a power of $200 \mathrm{~W}$ and an output voltage of $380 \mathrm{VDC}$. Also, the small signal model is presented, and the required transfer functions have been derived in order to design and implement the controllers that regulate the output current (detection of the peak current in the inductor) and the input voltage (PI controller) fixed by the reference imposed by a MPPT algorithm. Finally, the experimental results and conclusions are presented.
\end{abstract}

Keywords: Current-injected control, DC-DC converter, small signal model, maximum power point tracking (MPPT), photovoltaic systems.

\section{Introduction}

Sustainable energy development makes an essential part in the current energy systems research, in which solar energy plays an important role as one of the highest rising and promising technology. In the future, more than $40 \%$ of necessary energy in the world will be generated by photovoltaic arrays. Therefore, it is necessary to concentrate efforts in order to reduce the application costs and to enhance their performances [1]. In order to reach this last aspect, it is important to note that the output characteristic of a photovoltaic array is nonlinear and changes with solar irradiation and the temperature.

On the other hand, the PV systems are connected to the grid through converters. There are three basic topologies for connection of converters to the grid [2]. These are central inverters, string inverters and microinverters.

The microinverter is characterized by using a single photovoltaic panel for each power converter equipment, so each converter manages between $50 \mathrm{~W}$ peak and $400 \mathrm{~W}$ peak [3]. Since photovoltaic panels supply a very low voltage and a reduced number of them could be connected in series in the low power range, microinverters normally use a two-stage power topology composed by a DC-DC converter that feeds a power inverter at a high enough voltage level to generate the $\mathrm{AC}$ voltage.

In light of the above, and taking into account that the microinverter is composed by a DC-DC converter that takes the energy from a photovoltaic panel and the delivery to the inverter of injection to grid, it is proposed to operate with a

*E-mail address: cltruilllo@udistrital.edu.co

ISSN: $1791-2377 @ 2018$ Eastern Macedonia and Thrace Institute of Technology. All rights reserved.

doi:10.25103/jestr.114.17 push-pull converter and a current-injected control (CIC) based on a double loop scheme composed by PI controllers [4]. This topology offers isolation characteristics between the source and the load, and has a low number of components. Consequently, the object of study of this paper is focused on the design, modelling and implementation of the push-pull converter used in photovoltaic systems interconnected to the grid.

The paper is organized as follows: first the configuration of the circuit studied will be presented. Second, the pushpull circuit will be modeled in order to achieve the transfer functions necessary to develop the controllers. Third, the push-pull controllers will be designed in grid mode. Fourth, the MPPT algorithm will be implemented. Finally, the experimental results are presented and the conclusions are given.

\section{Push-pull configuration}

The scheme selected to develop the microinverter is supported on a double conversion topology as presented in [2] (DC-DC converter + Inverter), as well as the methodology for modelling the converter and designing the controllers.

In the present paper, only the corresponding to the DCDC converter (Push-pull converter) will be analyzed. Consequently, the inverter will be considered as a DC source for the push-pull, since it is responsible for regulating the input voltage of the inverter at 380VDC. In Fig. 1 the diagram of the push-pull converter with the control scheme implemented is shown. 


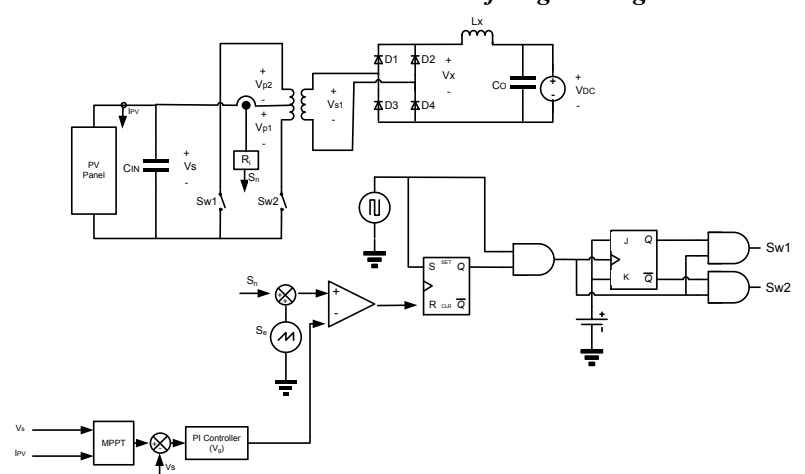

Fig. 1. CIC scheme of push-pull converter. Source: Authors

In the operation mode interconnected to grid, the objective focuses on the push-pull controllers causing this converter to extract the maximum power provided by the panels and deliver it to the inverter, and subsequently to the grid. Therefore, it is proposed to regulate the input voltage of the push-pull $\left(V_{s}\right)$ considering the signal imposed by the MPPT algorithm [5]. This voltage controller is implemented through PI controller. The current controller, which follows the reference set by the PI controller of the input voltage loop to the push-pull, was implemented using the currentinjected control (CIC) [6], this to avoid introducing DC levels that can cause the saturation of the transformer. Tab. 1 , presents the main electrical parameters of the proposed push-pull converter.

Table 1. Push-Pull electrical parameters.

\begin{tabular}{l|l}
\hline Parameter & Value \\
\hline Solar cell voltage variation (Vs) & $23 \mathrm{~V}-36.5 \mathrm{~V}$ \\
Minimum and maximum duty cycle (D) & $0.26-0.413$ \\
Solar cell current at MPP & $7.5 \mathrm{~A}$ \\
Input Capacitor (C $\mathrm{C}_{\mathrm{IN}}$ ) & $6.8 \mathrm{mF}$ \\
Output Inductor (Lx) & $22 \mathrm{mH}$ \\
Output Capacitor (Co) & $470 \mu \mathrm{\mu F}$ \\
Switching Frequency & $20 \mathrm{kHz}$ \\
Input Voltage & $28.7 \mathrm{~V}$
\end{tabular}

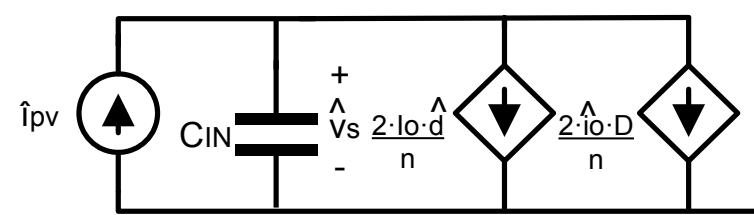

Nominal Power

Output Voltage (Vo)

Output Current

\section{Modelling of the Push-pull}

The DC-DC converters are nonlinear circuits, for this reason they must be linearized around an operating point to apply linear control techniques. The model developed in this paper is based on the PWM switch model [7], because this is a simple and versatile method to explain the small signal behavior of converters in continuous and discontinuous conduction mode. Additionally, it offers an equivalent linear circuit, from which the small signal and large signal analysis of the converter can be developed. Below are the models in small signal and the relations at the operation point of the push-pull converter. Fig. 2 shows the equivalent circuit around an operating point.

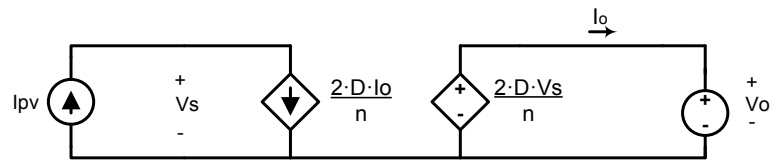

Fig. 2. Equivalent circuit of the push-pull converter.

From Fig. 2, the following relationships can be established (Eq. 1):

$V o=\frac{2 \cdot D \cdot V s}{n}$

Where $n$ is the inverse of the transformer turns ratio and $D$ the duty cycle of each one of the switches.

By linearizing around an operation point, a small signal model results, as shown by Fig. 3 [7]

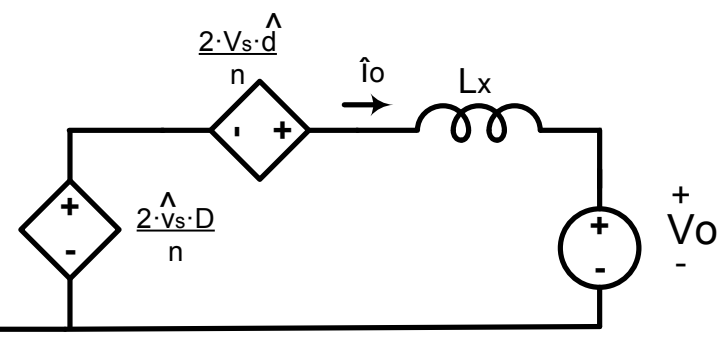

Figure 3. Push-Pull small signal model. Source: Authors

In the Fig. 3 the quantities in lower case with the "^»" symbol are terms of small signal and the quantities in capital letters are terms around the operation point.

The open loop transfer functions that relate the duty cycle to input voltage $\left(G_{V s-d}(s)\right)$, and duty cycle to the current in the output inductor $\left(G_{i o-d}(s)\right)$, can be extracted from the dynamic models set out in Fig. 2 and Fig. 3. These transfer functions are presented below:

The transfer function $G_{V s-d}(s)$ is defined as:

$$
G_{V S-d}(s)=\frac{\frac{4}{n^{2}} \cdot D \cdot V_{s}+s \cdot \frac{2}{n} \cdot L_{x} \cdot I_{o}}{-\frac{4}{n^{2}} \cdot D^{2}+s \cdot L_{x} \cdot k_{p v}-s^{2} \cdot L_{x} \cdot C_{I N}}
$$

Where $k_{p v}=I_{p v} / V_{s}$

The transfer function $G_{i o-d}(s)$ is defined as:
$G_{i o-d}(s)=\frac{\frac{2}{n}\left(k_{p v} \cdot V_{s}-s \cdot C_{i n} \cdot V_{S}+\frac{2}{n} \cdot D \cdot I_{o}\right)}{-\frac{4}{n^{2}} D^{2}+s \cdot k_{p v} \cdot L_{x}-s^{2} \cdot L_{x} \cdot C_{i n}}$

\section{Push-pull converter control}

The control scheme selected is the current-injected control (CIC) [6], [8]. By means of this control it is possible to control the peak of the current in the inductor or in the power transistor, which allows a protection, against overcurrent, inherent to the control. Additionally, with the DC-DC converter it is intended to control the input voltage from the reference imposed by the MPPT, which is a recent practice, since as mentioned before, the voltage was adjusted by directly varying the duty cycle [9]. Fig. 4 shows the current and voltage control loops for the push-pull. 


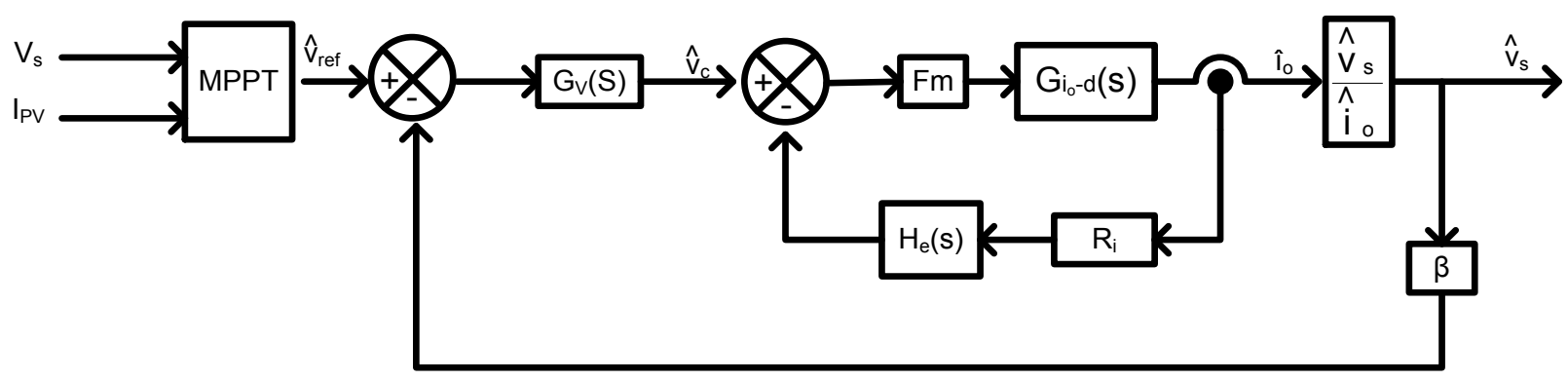

Fig. 4. Current and voltage control loops for the Push-Pull converter. Source: Authors

From Fig. 4 it is possible to define the inner current loop as $\operatorname{Ti}(s)=G_{i o-d}(s) \cdot R i \cdot H e(s) \cdot F_{M}$, and the outer output loop as $T v(s)=G_{v s-v c}(s) \cdot \beta \cdot G v(s)$. Where $G_{i o-d}(s)$ is the transfer function that relates the duty cycle to the output current, $R i$ is the current sensing gain $(\mathrm{Ri}=0.02 \mathrm{~V} / \mathrm{A}), \mathrm{He}(s)$ is the sampling gain, $F_{M}$ is the gain of the PWM modulator, $G_{v s-v c}(s)$ is the transfer function that relates the control voltage to the input voltage, $\beta$ is the gain of the voltage sensor and $G v(s)$ is the transfer function of the controller. The methodology for control design follows [8].

The first thing that will be determined in the CIC is the sampling gain $\mathrm{He}$ (s), which can be calculated from Eq. 4 . This gain is important for stability reasons because it adds two conjugates complex zeros of non-minimum phase at half the switching frequency to the current loop [6].

$H e(s)=\frac{s \cdot T_{s}}{e^{s \cdot T_{s}-1}} \approx 1+\frac{s}{\omega_{z} \cdot Q_{z}}+\frac{s^{2}}{\omega_{z}^{2}}$

Where:

$\omega_{z}=\frac{\pi}{T_{s}}=628$

$Q_{z}=-\frac{2}{\pi}=-0.6366$

Finally:

$H e(s)=2.533 \cdot 10^{-10} \cdot s^{2}-25 \cdot 10^{-6} \cdot s+1$

The following step is to determine the gain of the PWM modulator, $F_{M}$ depends on the sensing ramp ( $\left.S n\right)$ and the slope of the external stabilization ramp $(\mathrm{Se})$, which has a constant amplitude and frequency. Thus $F_{M}$ is obtained with the following expression (Eq. 7):

$$
\begin{aligned}
F_{M} & =\frac{1}{\left(S_{n}+S_{e}\right) \cdot T_{s}}=\frac{1}{m_{c} \cdot S_{n} \cdot T_{s}} \\
\mathrm{~m}_{\mathrm{c}} & =1+\frac{\mathrm{S}_{\mathrm{e}}}{\mathrm{s}_{\mathrm{n}}}
\end{aligned}
$$

Being $m_{c}$ a factor that establishes the level of stabilization provided by the external ramp. Therefore value for $S_{n}$ is obtained from the following equation (Eq. 8):

$S_{n}=\frac{\frac{1}{n^{2}} \cdot(1-2 \cdot D) \cdot V_{s} \cdot R_{i}}{L_{x}}=4174.5 \mathrm{v} / \mathrm{seg}$

In order to determine the value of $m_{c}$ that makes the current loop stable, it is necessary to perform a sweep of $\operatorname{Ti}(\mathrm{s})$ based on this parameter as it is shown by Fig. 5 .

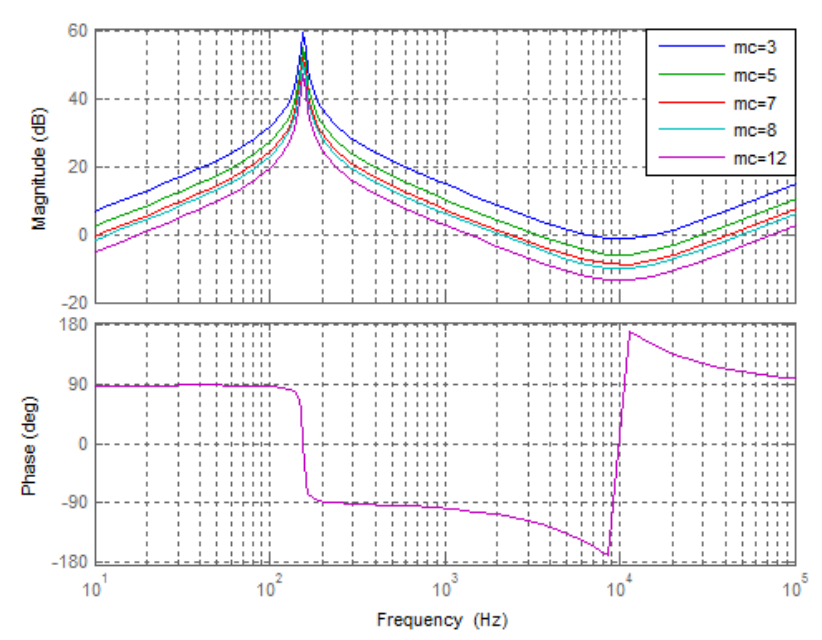

Fig. 5. Bode diagram of current loop Ti(s) for several values of mc.

As shown in the figure, the crossover frequency decreases as the value of $m_{c}$ increases. Considering this and the stability of the loop, was chosen $m_{c}=7$. For this value the phase margin is $69.1^{\circ}$ and bandwidth of $2.32 \mathrm{kHz}$.

The next step is to obtain the voltage controller $G_{v}(s)$, for which the value of $\beta=0.05$, and the transfer function $G_{V s-}$ $V_{c}(s)$ must be taken into account. This transfer function can be determined through equations (2) and (3), and the auxiliary function that relates the output voltage of the voltage controller to the current in the inductor. This transfer function is presented in Eq. 9.

$$
G_{i_{L x}-v_{c}}(s)=\frac{\hat{i}_{L x}}{\hat{v}_{C}}=\frac{T_{i}(s)}{R_{i} \cdot\left(1+T_{i}(s)\right)}
$$

The transfer function $G_{V s-V c}(s)$ is defined as

$$
G_{v_{g}-v_{c}}(s)=\frac{\hat{v}_{g}}{\hat{i}_{L x}} \cdot \frac{\hat{i}_{L x}}{\hat{v}_{C}}=\frac{\hat{v}_{g}}{\hat{d}} \cdot\left(\frac{\hat{i}_{L x}}{\hat{d}}\right)^{-1} \cdot \frac{\hat{i}_{L x}}{\hat{v}_{C}}=\frac{\hat{v}_{g}}{\hat{v}_{C}}
$$

The voltage controller was implemented through a PI controller presented in Eq. 11.

$$
\mathrm{Gv}(\mathrm{s})=\mathrm{Kp}+\frac{\mathrm{Ki}}{\mathrm{s}}=8.558+\frac{611.3}{\mathrm{~s}}
$$

Fig. 6 shows the Bode plot for the voltage loop with the proposed controller, a phase margin of $88.8^{\circ}$ and a bandwidth of $300 \mathrm{~Hz}$ are achieved. This crossover frequency for the outer voltage loop was selected so that this value to 
be much smaller than the crossover frequency of the inner current loop, but not too small to slow down the control action, because the voltage loop should be much faster than the operating frequency of the MPPT in order to prevent interactions between them.

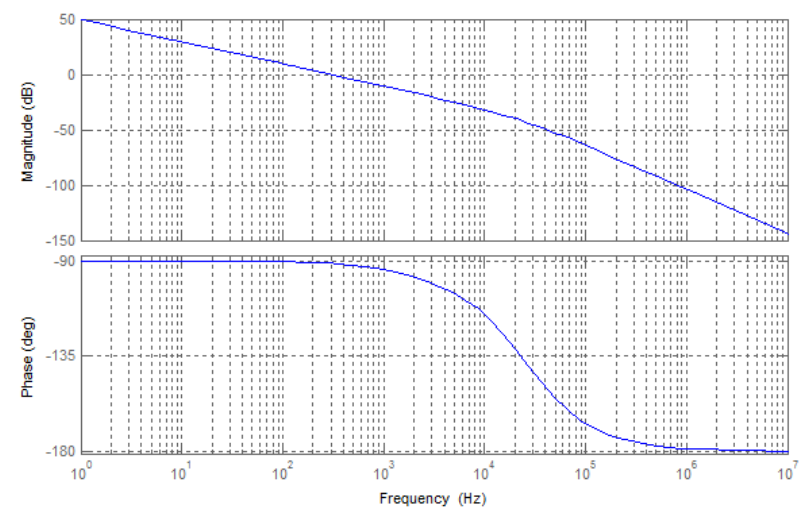

Fig. 6. Bode diagram of outer voltage control loop Tv (s).

\subsection{Maximum power point tracking (MPPT)}

The reference imposed to the outer voltage loop is set by the MPPT technique. The MPPT technique is used in photovoltaic (PV) systems to maximize the photovoltaic array output power, independently of the load electrical characteristics and for different environmental conditions [10]. However, the photovoltaic power characteristic is nonlinear, because it varies with the level of solar irradiation and temperature as shown in Fig. 7, making the extraction of maximum power a complex task. For this reason, several methods for extracting the maximum power have been proposed as Fixed Duty Cycle, Constant Voltage, Perturb and Observe (P\&O), Incremental Conductance (IC), Ripple Correlation, fuzzy logic, neural network and others [11], [12].
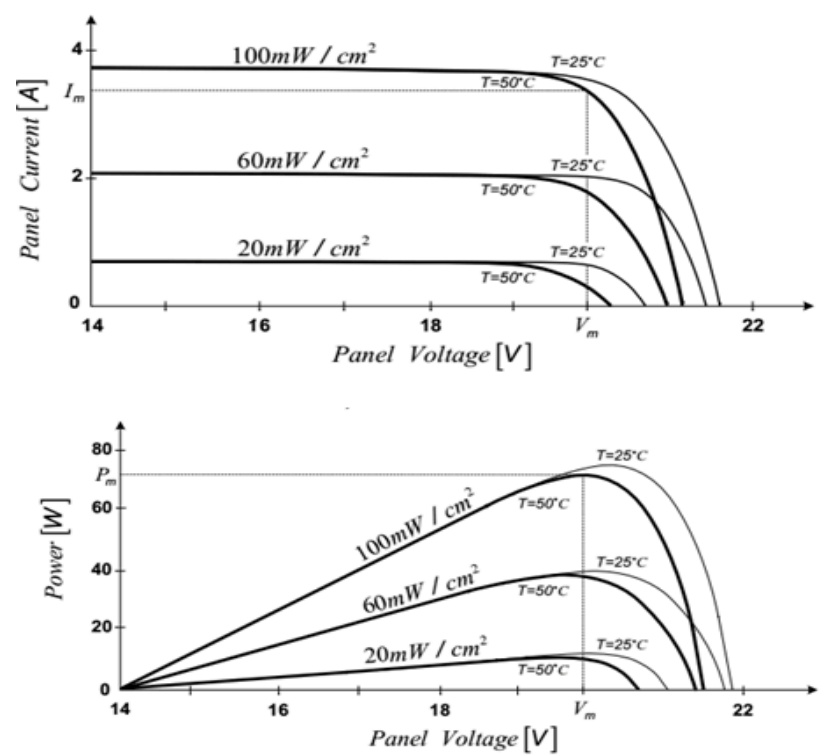

Fig 7. PV Current versus voltage characteristic (top) and Power characteristic for different levels of irradiation (bottom) [13]

\section{- Perturb and Observe ( $P \& O)$ Method}

The MPPT technique selected was "Perturb and Observe $(\mathrm{P} \& \mathrm{O})$. This technique was chosen because it is widely used for its simplicity of operation and the few variables to be measured for effective results in tracking the maximum power. $\mathrm{P} \& \mathrm{O}$ method operates periodically incrementing or decrementing the array terminal voltage, through the converter duty cycle and then comparing the power obtained in the current cycle with the power of the previous perturbation cycle. Therefore, if the actual measured power is greater than the previous cycle, the disturbance will continue in the same direction in the next cycle. That is, if the array terminal voltage varies and power increases, the control system moves the operating point of the PV array in that direction; otherwise change the operating point in the opposite direction. Fig. 8 shows the flowchart of this algorithm.

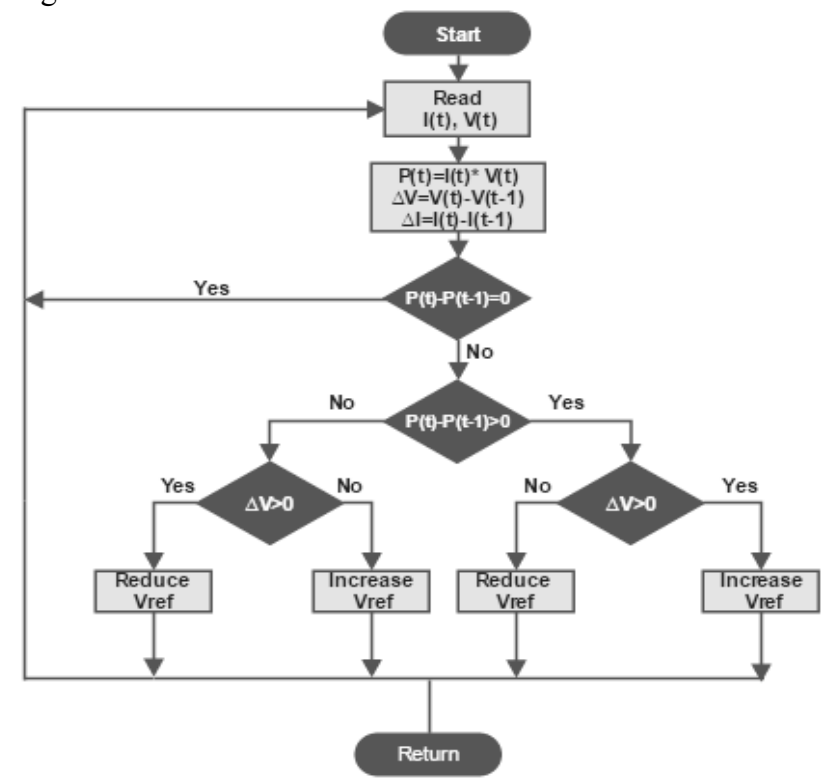

Fig. 8. Flowchart of $\mathrm{P} \& \mathrm{O}$ algorithm.

\section{Experimental results}

The push-pull was implemented taking into account the electrical characteristics presented in Table 1, the current control was developed with the integrated circuit UC3825, while the PI voltage controller and the MPPT algorithm were developed in the Texas Instruments DSP TMS320F28335.

In order to validate the operating of the control loops and the MPPT algorithm, a DC AGILENT N8762A power supply was used to emulate the photovoltaic panel.

In the beginning, for an adequate operation of the current loop, the PWM signal must be generated correctly, consequently it is necessary to measure the current in the transistors and the external stabilization ramp (Fig. 1). The external ramp stabilizes the inner loop current, for that reason, this signal must be combined with the sensed ramp. These signals are shown in Fig. 9.

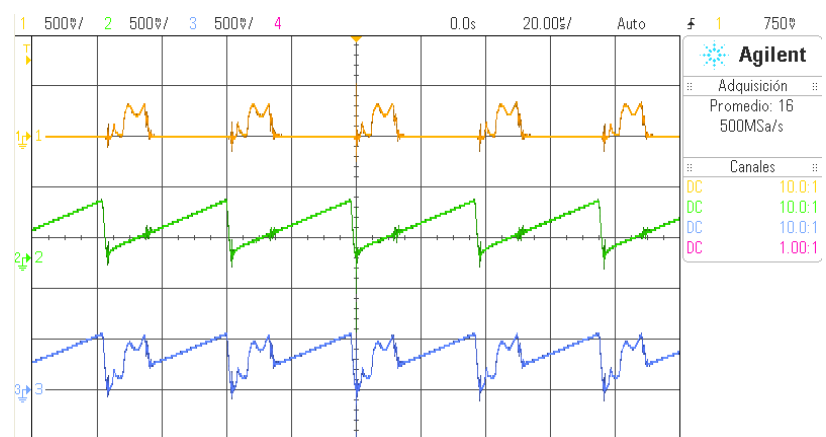

Fig. 9. Sensed ramp $S_{n}$ (top), external compensation ramp $S_{e}$ (central) and Sum of the sensed ramp and external compensation ramp $\left(S_{n}+S_{e}\right)$ (bottom). 
The PWM signal generated is shown in Fig. 10. It should be noted that the PWM modulator output takes a high level when the sensed ramp $\left(S_{n}\right)$ is activated and changes state when the reference voltage equals the sum signal of the ramps.

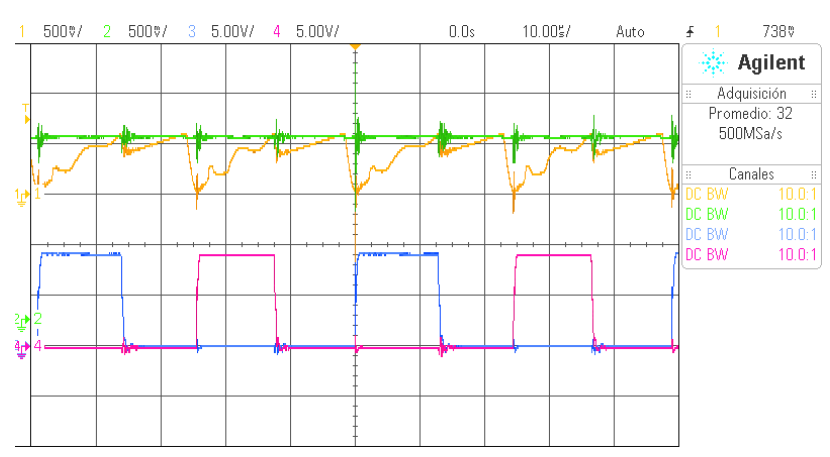

Fig. 10. Sum of the sensed ramp and external compensation ramp $\left(S_{n}+S_{e}\right)$ and reference voltage (top), PWM signal (bottom).

Fig. 11 shows how the output current of the push-pull is adjusted to changes in irradiance which are reflected in changes of input current from the panel. In addition, it should be noted that the input voltage from the panel remains constant about $27.34 \mathrm{~V}$. From these results the correct operation of the voltage control loop is verified.

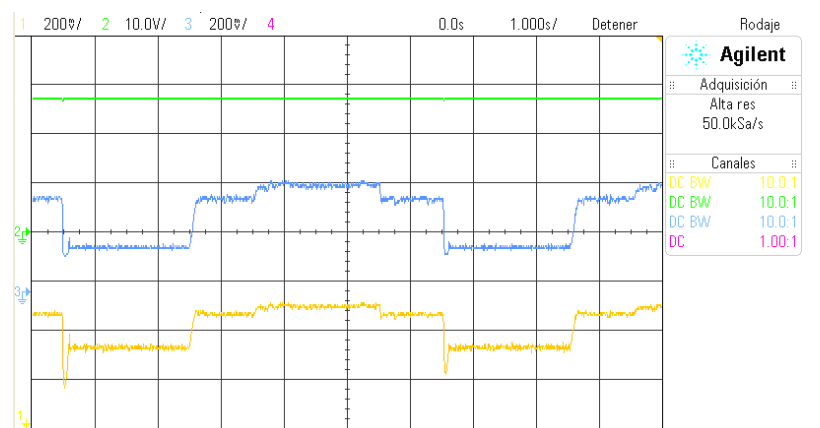

Fig 11. Panel voltage (top), current panel variations (central) and output current of Push-pull converter (bottom).

Finally, the main MPPT results are presented. The value of perturbation (Vref) is $500 \mathrm{mV}$ and the sampling frequency was adjusted at $50 \mathrm{~Hz}$ in order to avoid it to interfere with the frequency of voltage controller; this value was selected after performing different tests and analyzing the results derived from simulation. Importantly, this sampling frequency achieves a quicker response time to changes in irradiance.
In Fig. 12 shows the changes of voltage and current according different irradiance conditions. The P\&O algorithm continuously perturbs the operating point of the system causing the PV array output voltage to fluctuate around the MPP voltage as shown. Therefore P\&O algorithm changes the reference voltage which is controlling, the first step being to VMPP $\approx 30 \mathrm{~V}$ and then gradually increasing it to $31 \mathrm{~V}$.

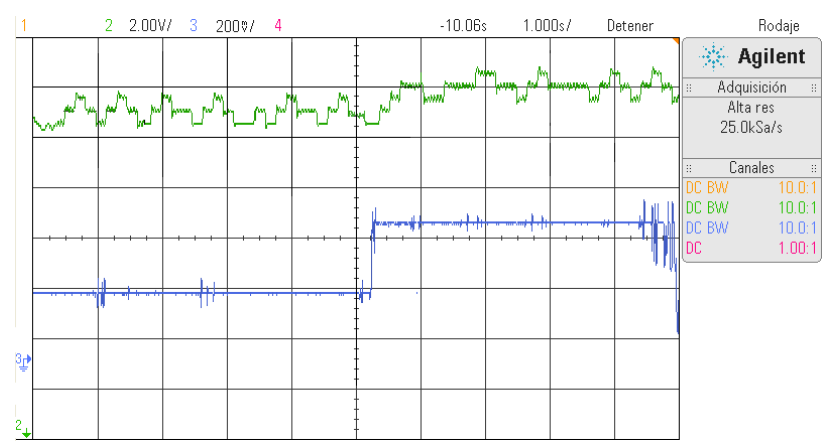

Fig. 12. Panel voltage (top) and current panel (bottom) with the action of P\&O MPPT algorithm.

\section{Conclusion}

In this paper was presented the design, modelling and implementation of a push-pull converter for operation in an interconnected grid mode, powered by a photovoltaic panel. A small signal model of the converter were obtained, this model allowed to calculate all transfer functions of interest to design the control loops that make up the current-injected control. In addition a $P \& 0$ algorithm was development with the aim of extracting maximum power from the panel. The MPPT technique and the control loops of the push-pull were experimentally tested with irradiance changes simulated through the programmable current sources; this allowed validating the proper operation of the converter.

\section{Acknowledge}

This work is supported by project entitled "Low and Medium capacity battery charger with low current THD, high power factor and high efficiency for electric vehicles" sponsored by COLCIENCIAS aims to support initiatives for the developing of novel technologies in the field of energy storage.

This is an Open Access article distributed under the terms of the Creative Commons Attribution License

\section{References}

1. A. Malinowski, J. Leon, H. Abu-Rub, "Solar Photovoltaic and Thermal Energy Systems: Current Technology and Future Trends". Proceedings of the IEEE, 105(11), pp. 2132-2146, (2017).

2. S. Öztürk, I. Çadırcı, "A Generalized and Flexible Control Scheme for Photovoltaic Grid-Tie Microinverters", IEEE Transactions on Industry Applications, 54(1), (2018).

3. L. Cavanini, G. Cimini, G. Ippoliti, A. Bemporad, "Model predictive control for pre-compensated voltage mode controlled DC-DC converters". IET Control Theory \& Applications, 11(5), pp. 2514-2510, (2017).

4. T. Pavlovic, T. Bjazic, Z. Ban. "Simplified Averaged Models of DC-DC Power Converters Suitable for Controller Design and Microgrid Simulation". IEEE Transactions on Power Electronics, 28(7), pp. 3266-3275, (2013).
5. T. Esram, P. Chapman. "Comparison of Photovoltaic Array Maximum Power Point Tracking Techniques". IEEE Transactions on Energy Conversion, 22 (2), pp.439-449, (2007).

6. D. Sable, R. Ridley. "Comparison of performance of single-loop and current-injection control for PWM converters that operate in both continuous and discontinuous modes of operation". IEEE Transactions on Power Electronics, 7(1), pp.136-142, (1992).

7. E. Van Dijk, et.al, "PWM-Switch Modeling of DC-DC Converters" IEEE Transactions on Power Electronics, 10(6), pp. 659-665, (1995).

8. G. Garcerá, P. J. Carbonell, A. Abellán, "Sensibility Study of the Control Loops of Voltage and Current Mode Controlled DC-DC Converters by means of Robust Parametric Control Theory". IEEE International Symposium on Industrial Electronics, 2, pp. $613-$ 617, (1999). 
Angie Alejandra Rojas Aldana, Oscar Ernesto Barrera Beltrán and Cesar Leonardo Trujillo Rodríguez/

Journal of Engineering Science and Technology Review 11 (4) (2018) 132 - 137

9. G. Vijayakumar, R. Anita, "Optimal Operation of Photovoltaic System with a DC-DC Boost Converter FED SAF Using ICos $\varphi$ Algorithm". Journal of Engineering Science and Technology Review, 7(3), pp 7-16, (2014).

10. E. Koutroulia, K. Kalaitzakis, N. C. Voulgaris, "Development of a Microcontroller-Based, Photovoltaic Maximum Power Point Tracking Control System." IEEE Transactions on Power Electronics, 16(1), (2001).

11. T. Esram, P.L. Chapman, "Comparison of Photovoltaic Array Maximum Power Point Tracking Techniques". IEEE Transactions on Energy Conversion, 22, pp. 439-449, (2007).

12. P. C. Chen, P. Y. Chen, Y. H. Liu, J. H. Chen, Y. F. Luo, “A comparative study on maximum power point tracking techniques for photovoltaic generation systems operating under fast changing environments". Solar Energy, 119, pp. 261-276, (2015).

13. E. Durán, J. Galán, M. Sidrach-de-Cardona, F. Segura. “An Application of Interleaved DC-DC Converters to obtain I-V Characteristic Curves of Photovoltaic Modules". 34th Annual Conference of IEEE Industrial Electronics, pp. 2284-2289, (2008). 